\title{
Why Are There Agulhas Rings?
}

\author{
THIERRY PICHEVIN \\ SHOM/CMO, Brest, France \\ DORON NOF \\ Department of Oceanography and the Geophysical Fluid Dynamics Institute, The Florida State University, Tallahassee, Florida \\ JOHANN LUTJEHARMS \\ Department of Oceanography, University of Cape Town, Rondebosch, South Africa
}

(Manuscript received 31 March 1997, in final form 7 May 1998)

\section{ABSTRACT}

\begin{abstract}
The recently proposed analytical theory of Nof and Pichevin describing the intimate relationship between retroflecting currents and the production of rings is examined numerically and applied to the Agulhas Current. Using a reduced-gravity 11/2-layer primitive equation model of the Bleck and Boudra type the authors show that, as the theory suggests, the generation of rings from a retroflecting current is inevitable. The generation of rings is not due to an instability associated with the breakdown of a known steady solution but rather is due to the zonal momentum flux (i.e., flow force) of the Agulhas jet that curves back on itself. Numerical experiments demonstrate that, to compensate for this flow force, several rings are produced each year. Since the slowly drifting rings need to balance the entire flow force of the retroflecting jet, their length scale is considerably larger than the Rossby radius; that is, their scale is greater than that of their classical counterparts produced by instability.

Recent observations suggest a correlation between the so-called "Natal Pulse" and the production of Agulhas rings. As a by-product of the more general retroflection experiments, the pulse issue is also examined numerically using two different representations for the pulses. The first is a meander pulse (i.e., the pulse is similar to a meander) and the second is a transport pulse. It is shown that, in this model, there is no obvious relationship between the presence of Natal pulses and the production of rings.
\end{abstract}

\section{Introduction}

All western boundary currents have been observed to shed vortices at their downstream terminations. Examples are the Gulf Stream (Richardson 1983), the Kuroshio (Solomon 1978), the East Australian Current (Nilsson and Cresswell 1980), the Brazil Current (Legeckis and Gordon 1982), and the Agulhas Current (Lutjeharms 1981). Compared to the shedding of rings observed elsewhere, that of the North Brazil Current (NBC) and the Agulhas is unusual in two important respects. First, because of the continental configuration, these rings cause a substantial unidirectional leakage of tropical and subtropical waters from one ocean to the other. This process may be a key component of the global thermohaline circulation cell (Gordon 1986).

Corresponding author address: Professor Doron Nof, Department of Oceanography (4320), The Florida State University, Tallahassee, FL 32306-4320.

E-mail: nof@ocean.fsu.edu
Second, both North Brazil Current rings and Agulhas rings are anticyclonic, leading to a distinct vorticity contribution to the receiving ocean.

Traditionally, most eddy formation processes have been associated with currents and frontal instabilities. ${ }^{1}$ Such instabilities generate meanders that grow, close upon themselves, and then pinch off. The separation process of western boundary currents and their subsequent poleward intrusion also produces rings (e.g., see Nilsson et al. 1977; Nilsson and Cresswell 1980; Olson 1991). Both the former and the latter mechanisms are probably the correct formation mechanisms for many eddies and rings in the ocean (e.g., Gulf Stream and Kuroshio rings, the Brazil and East Australia Current rings). However, retroflection eddies (e.g., North Brazil Current rings, Agulhas rings) are unique and do not

\footnotetext{
${ }^{1}$ By "instability" we mean here the breakdown of a known steady solution. With this definition, a simple transfer of momentum from an observed "mean" flow to eddies is not necessarily associated with instability because the mean flow may not be steady.
} 


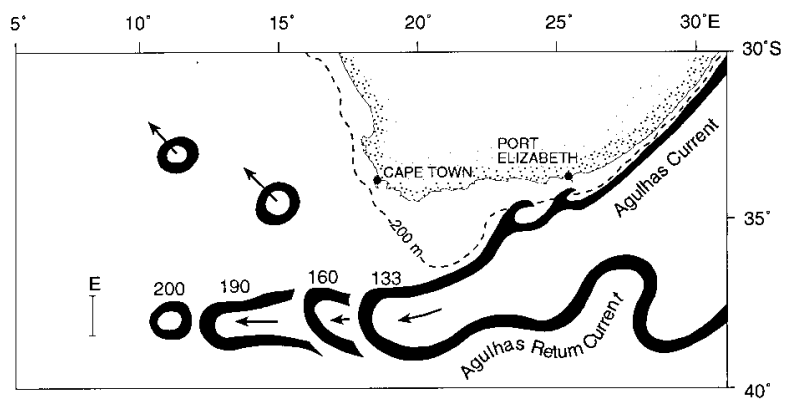

FIG. 1. Conceptual portrayal of the southern Agulhas Current, the Agulhas retroflection, and the Agulhas Return Current. The progradation of the Agulhas retroflection loop is shown for days during 1978 (according to Lutjeharms and van Ballegooyen 1988b). The bar marked $\mathbf{E}$ shows the westernmost position to which the retroflection loop has been observed to extend (Lutjeharms 1988). The 200-m isobath, showing the width of the continental shelf, is given as a broken line. The large meander in the path of the Agulhas Return Current at $27^{\circ} \mathrm{E}$ is due to the presence of a bottom obstruction, the Agulhas Plateau.

belong to either of the above categories because they correspond to a primarily zonal protrusion of the parent current. Also, retroflection rings are always generated in the same location, suggesting a new, geographically controlled, formation mechanism.

This suggestion is supported by the observations that retroflection rings are typically larger than rings produced by instability. We focus here on an eddy generation process associated with such a geographical control, a larger length scale, and a zonal retroflection. The essential elements of the process have been newly formulated analytically by Nof and Pichevin (1996, hereafter referred to as NP) for the NBC. They showed that retroflection rings result from a paradox associated with a momentum imbalance generated by a zonal jet that curves back on itself. Here, we focus on the Agulhas Current (Fig. 1) and present new sets of numerical experiments describing the "retroflection paradox" and the ring shedding process in detail.

\section{a. Observational background}

In its southern reaches, the Agulhas Current is a narrow [ $100 \mathrm{~km}$ (Gordon et al. 1987)] and deep current $(\sim 1500 \mathrm{~m})$ with surface velocities in excess of $1.5 \mathrm{~m}$ $\mathrm{s}^{-1}$ (Duncan and Schladow 1981) and a (still debatable) volume flux of roughly $70 \mathrm{~Sv}$. It exhibits increasing tendencies to meander as it moves past the widening continental shelf south of Africa (Lutjeharms et al. 1995). Ultimately, south of about $37^{\circ} \mathrm{S}$ (Fig. 1), it runs past the southernmost point of the shelf, forms rings (Duncan 1968), and retroflects to form the Agulhas Return Current (Bang 1970; Harris and van Foreest 1978; Gordon 1985; Lutjeharms and Ansorge 1999, submitted to J. Phys. Oceanogr.). These aspects have been known for some time. In fact, some of them can be seen even in the nineteenth century surface current charts (Pearce
1977) and in very early hydrographic studies (Dietrich 1935).

The retroflection point is not geographically stationary but progrades westward at increasing rates (Lutjeharms and van Ballegooyen 1988a) until a ring occlusion takes place. This process has been studied using satellite remote sensing in the thermal infrared (Lutjeharms 1981) and altimetry (Feron et al. 1992). It has also been observed hydrographically at sea (Lutjeharms and Gordon 1987). The progradation rate of the Agulhas retroflection loop varies between 7 and $15 \mathrm{~km} \mathrm{day}^{-1}$ (Olson and Evans 1986). The maximum distance to which the loop protrudes into the South Atlantic (Lutjeharms 1988) before a ring is shed (Fig. 1) is also quite variable. This process is reasonably well represented in most eddy-resolving, global circulation models (e.g., Semtner and Chervin 1992; Lutjeharms and Webb 1995) although such models do not explain the eddy generation process in detail.

Ring shedding at the Agulhas retroflection occurs at irregular intervals, but in general about six times per year. Lutjeharms and van Ballegooyen (1988a) have estimated six to nine times per year, Feron et al. (1992) about four to eight, and Goni et al. (1997) about two to six. Agulhas rings have a diameter of 200 to $280 \mathrm{~km}$, reach a depth of $1100 \mathrm{~m}$ (Duncombe Rae 1991), and have azimuthal speeds of about $0.6 \mathrm{~m} \mathrm{~s}^{-1}$ (Duncombe Rae 1991). They drift northwestward into the South Atlantic at a rate of about 5-8 $\mathrm{km} \mathrm{day}^{-1}$, and estimates of the resulting volume flux vary between 3 and $15 \mathrm{~Sv}$ $\left(\mathrm{Sv} \equiv 10^{6} \mathrm{~m}^{3} \mathrm{~s}^{-1}\right)$ (Gordon et al. 1992).

Gordon et al. (1987) arrived at an estimate of $10 \mathrm{~Sv}$ for water entering the Atlantic in 1983 to feed part of the imbalance associated with the water in the southeast Atlantic. Whitworth and Nowlin (1987) observed a much larger Indian-Atlantic transport of $20 \mathrm{~Sv}$ in 1984 , but it is not obvious that the two correspond to the same water so that it is not clear how the two amounts can be compared. Bennett (1988), on the other hand, arrived at lower values of 6.3 and $9.6 \mathrm{~Sv}$ for 1983 and 1984. From these amounts that enter the Atlantic, Bennett argues that only $2.8 \mathrm{~Sv}$ are warm Indian Ocean water. Stramma and Peterson (1990) find an Indian to Atlantic transfer of $8 \mathrm{~Sv}$ whereas Gordon and Haxby's (1990) inventory of rings suggests a transport of 10-15 Sv. The McCartney and Woodgate-Jones (1991) definition of an eddy corresponds to a smaller feature than that considered by Gordon and Haxby (1990) and, consequently, they arrive at a smaller estimate of 2-5 Sv. In a subsequent article, Gordon et al. (1992) proposed a circulation pattern that is somewhat different from Gordon's (1986) original suggestion. In their new scenario, much of the Indian Ocean surface water, which enters the South Atlantic via the Benguela Current and Agulhas rings, recirculates and exits the South Atlantic. Byrne et al. (1995) suggest that the rings carry at least $5 \mathrm{~Sv}$ to the South Atlantic, and Goni et al. (1997) suggest a similar transport. Accordingly, we shall assume here 
that the Indian-Atlantic mass flux due to rings is about $5 \mathrm{~Sv}$.

Using familiar formulas for $\beta$-induced drift of rings (e.g., Nof 1981) one easily finds that most of the observed ring drift ( $80 \%$ or so) is due to advection by the mean surrounding circulation and due to some other, yet unclear, propulsion mechanism rather than self propulsion due to $\beta$ (e.g., see Dewar and Galliard 1994; Radko and Stern 1998). This means that perhaps $1-2 \mathrm{~Sv}$ are due to the $\beta$-induced migration and the remaining 3-4 $\mathrm{Sv}$ influx is due to another cause of migration.

\section{b. Theoretical background}

Presently, there is no agreement on why the Agulhas Current retroflects. It is clear, however, that the African continent terminates prior to the vanishing of the wind stress curl (Veronis 1973) so that the common explanation of detachment due to no interior transport does not apply. Explanations for the retroflection range from strong continental curvature causing a surfacing thermocline (Ou and de Ruijter 1986) to bottom topography (Matano 1996). The interested reader is referred to Matano (1996) for a thorough review of previous retroflection theories, and to de Ruijter (1982), Lutjeharms and van Ballegooyen (1984, 1988a,b), de Ruijter and Boudra (1985), Boudra and de Ruijter (1986), Boudra and Chassignet (1988), and Chassignet and Boudra (1988). For the purpose of our present study we shall take the presence of retroflection for granted; that is, we shall not be asking the question of why the retroflection occurs but rather ask the question of what happens if a retroflection is somehow set up. We chose to do so because the question of why Agulhas rings are formed is even less clear than why there is a retroflection.

Ou and de Ruijter (1986) have suggested that Agulhas retroflection rings are produced due to curvature constraints. Although their model is useful and may shed some light on the separation process, it does not provide much information regarding the ring generation itself. The same can be said of de Ruijter and Boudra (1985), Boudra and de Ruijter (1986), and Matano (1996). The only study that is specifically directed at ring dynamics is that of Boudra and Chassignet (1988) and Chassignet and Boudra (1988). They argue that coastal friction, as well as inertia and baroclinicity in the overshooting Agulhas, play important roles in the frequency of ring formation. It has also been suggested that the downstream passage of a Natal pulse, a solitary meander of the trajectory of the Agulhas Current, may induce a ring formation (Lutjeharms and Roberts 1988). Recent investigations using altimetric data to monitor the current (van Leeuwen et al. 1999) have suggested that the passage of every single pulse leads to the shedding of a ring when the pulse reaches the retroflection. However, rings may also be spawned without the intercession of a Natal pulse. As just mentioned, NP have shown an-

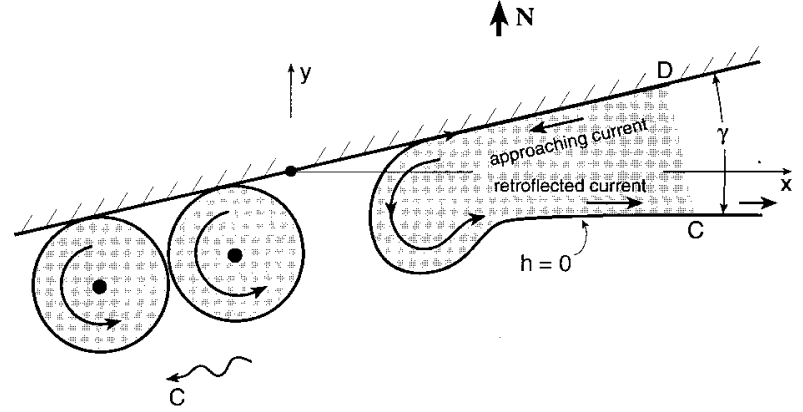

FIG. 2. The paradox and its resolution (in the Southern Hemisphere) according to NP. To simplify the analysis, NP considered the cases where there is no coastline tilt (i.e., $\gamma=0$ ). To compensate for the westward momentum flux (or flow force) created by the approaching and the retroflected currents, westward propagating anticyclonic rings are generated. In this scenario, the eddies exert an eastward momentum flux analogous to the backward push associated with a firing gun. The "wiggly" arrow denotes migration.

alytically that, without the production of rings, retroflection leads to an unbalanced flow force resulting in a paradox. [A similar process is discussed in Pichevin and Nof (1997) where it is applied to a channel flow.]

\section{c. Present approach}

We use numerical experiments to examine the NP paradox in detail and illustrate that it is responsible for the generation of the Agulhas rings; that is, we show that there cannot be a retroflection without the generation of rings. This paper is organized as follows. In section 2 we shall briefly review NP's results and apply them to the Agulhas Current. We shall then present a set of 18 numerical experiments performed with the Bleck and Boudra (1986) reduced-gravity numerical model (section 3). These experiments confirm our analysis and represent a broad range of parameters. Four numerical experiments corresponding to the Natal pulse are discussed in section 4 , and the results are summarized in section 5 .

\section{Theoretical overview}

This section summarizes briefly the NP model and discusses its application to the Agulhas. We consider a westward flowing boundary current (with density $\rho$ ) embedded in an infinitely deep, stagnant lower layer (with a density $\rho+\Delta \rho$ ). The current retroflects at some point and turns eastward (Fig. 2) after separating from the wall; as mentioned, the cause of the retroflection is not important for the present analysis.

Using the nonlinear shallow-water equations for an inviscid fluid, NP have shown analytically that the approaching and retroflecting currents exert a westward momentum flux that cannot be balanced in a purely steady-state situation (i.e., a state where the approaching current merely retroflects and flows eastward). They 
termed this aspect the retroflection paradox and demonstrated that, to balance the momentum flux and resolve this paradox, westward drifting rings are generated on the western side of the retroflection. During their formation, the westward moving rings exert an eastward momentum flux analogous to the backward force associated with a firing gun. NP found the eddy generation periodicity to be $O\left(f \varepsilon^{5 / 6}\right)^{-1}$ [where $\varepsilon=\beta R_{d} / f_{0} \sim$ $O(0.01)$ and $R_{d}$ is the Rossby radius] and the ring radius to be $O\left(R_{d} / \varepsilon^{1 / 6}\right)$. This shows that the generation time is long and that the rings are larger than the rings produced by classical instability processes $\left[O\left(R_{d}\right)\right]$.

The Nof and Pichevin computations were made using integrated constraints (without solving for the detailed ring generation process). Specifically, the momentumflux constraint was obtained by integrating the $x$-momentum equation over space and time and the conservation of mass and potential vorticity were also used. It turns out that, in addition to these constraints, a closure condition is required, and to satisfy this, the exiting rings were considered to be "kissing" each other. Clearly, there is no reason for the actual rings to touch each other, but this closure condition provides an upper bound on the ring's volume flux and a lower bound on both the periodicity and size.

Application of the NP analytical solutions to the Agulhas Current with numerical values of (admittedly small) $40 \mathrm{~Sv}$ transport, a reduced gravity of $1.5 \times 10^{-2}$ $\mathrm{m} \mathrm{s}^{-2}$, a basic undisturbed depth of $653 \mathrm{~m}$, a current potential vorticity depth ${ }^{2}$ of $2125 \mathrm{~m}$ (yielding a relative vorticity of $-0.2 f$ at the center of the resulting rings), $\beta$ of $2 \times 10^{-11} \mathrm{~m}^{-1} \mathrm{~s}^{-1}$, and a Coriolis parameter of 8 $\times 10^{-5} \mathrm{~s}^{-1}$ gives a periodicity of 164 days, a radius of $227 \mathrm{~km}$, a drift of $3 \mathrm{~cm} \mathrm{~s}^{-1}$, and an upper-bound ring volume flux of $11 \mathrm{~Sv}$ (which is $28 \%$ of the inflow). The periodicity (164 days) is considerably larger than the observed one (60 days), and so is the predicted upper bound of the eddy mass flux (11 Sv compared to $5 \mathrm{~Sv}$ ). The size of the calculated rings is also larger than the observed one (a radius of $227 \mathrm{~km}$ instead of roughly $130)$. With an artificially large $\beta\left(6 \times 10^{-11} \mathrm{~m}^{-1} \mathrm{~s}^{-1}\right.$ instead of $\left.2 \times 10^{-11} \mathrm{~m}^{-1} \mathrm{~s}^{-1}\right)$ and a current potential vorticity depth of $1375 \mathrm{~m}$ (yielding again a relative vorticity of $-0.2 f$ at the resulting ring's center) we get a periodicity of 66 days, a somewhat more reasonable (though still relatively large) radius of $190 \mathrm{~km}$, a more reasonable drift of $6.4 \mathrm{~cm} \mathrm{~s}^{-1}$, and a larger upper bound volume flux of $13 \mathrm{~Sv}$.

It should be pointed out that, because of the tendency of nonlinear frontal models such as ours to produce large speeds along the front, we have chosen a relatively low value for the mass flux $(40 \mathrm{~Sv})$. Even with this reduced value, the orbital speed along the eddies' edge is still

\footnotetext{
${ }^{2}$ Note that the potential vorticities of the basin and current are not necessarily identical.
}

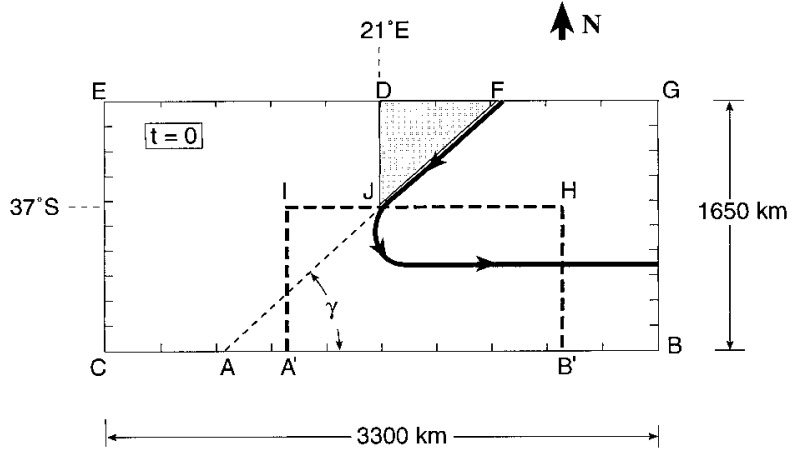

FIG. 3. The domain of our numerical simulations and the initial position of the current (thick solid arrow). The southern tip of Africa is idealized as a triangle (shaded area) and an inflow is prescribed at the northern boundary along the east coast of Africa. The initial condition is a current flowing along Africa and retroflecting at a given latitude to flow eastward. The eastern and western boundaries have open boundary conditions. The basin size is $1650 \mathrm{~km} \times 3300 \mathrm{~km}$. The thick broken line denotes the boundary of the region for which the computed mass fluxes and momentum fluxes are later shown. The thin broken line (AJ) will later be used to describe variables associated with the Natal pulse. $\gamma$ is the inclination of the east African coast.

large $\left(3.9 \mathrm{~m} \mathrm{~s}^{-1}\right)$ but this is typical for such models (e.g., see Flierl 1979; Pichevin and Nof 1997). Note, however, that the results are not very sensitive to the choice of the upstream mass flux and, aside from the high speed along the edge, even $70 \mathrm{~Sv}$ give reasonable values for all the variables. Finally, note that, for the above numerical values, $\varepsilon=0.00975$ so that $\varepsilon^{1 / 6}=$ 0.46 implying a potentially nonnegligible error in the computations. Recall, however, that using such a large value for an expansion parameter is not unusual. Quasigeostrophic theory, which requires a small Rossby number, is routinely applied to eddies and rings whose Rossy number is as large as unity. Finally, it should be pointed out that the NP theory cannot be applied to rings that migrate meridionally (e.g., rings resulting from the East Australia Current described by Nilsson and Cresswell 1980) rather than zonally because of the additional ( $\beta$-induced) meridional forces that enter the problem.

\section{Numerical confirmation}

\section{a. The model}

To examine the validity of our findings, 18-numerical experiments using the Bleck and Boudra (1986) reduced-gravity isopycnic model were performed on a $\beta$ plane (see Fig. 3 and Table 1). The African continent is idealized as a triangle whose eastern boundary has an inclination $\gamma$. The boundary conditions are (i) freeslip along the African coast, as well as the northern and southern boundaries, and (ii) Orlanski second-order open boundary conditions along the eastern and western boundaries with an additional sponge layer 10 points wide. As we shall see, the streamlines are not disturbed when the fluid leaves the basin, suggesting that these 


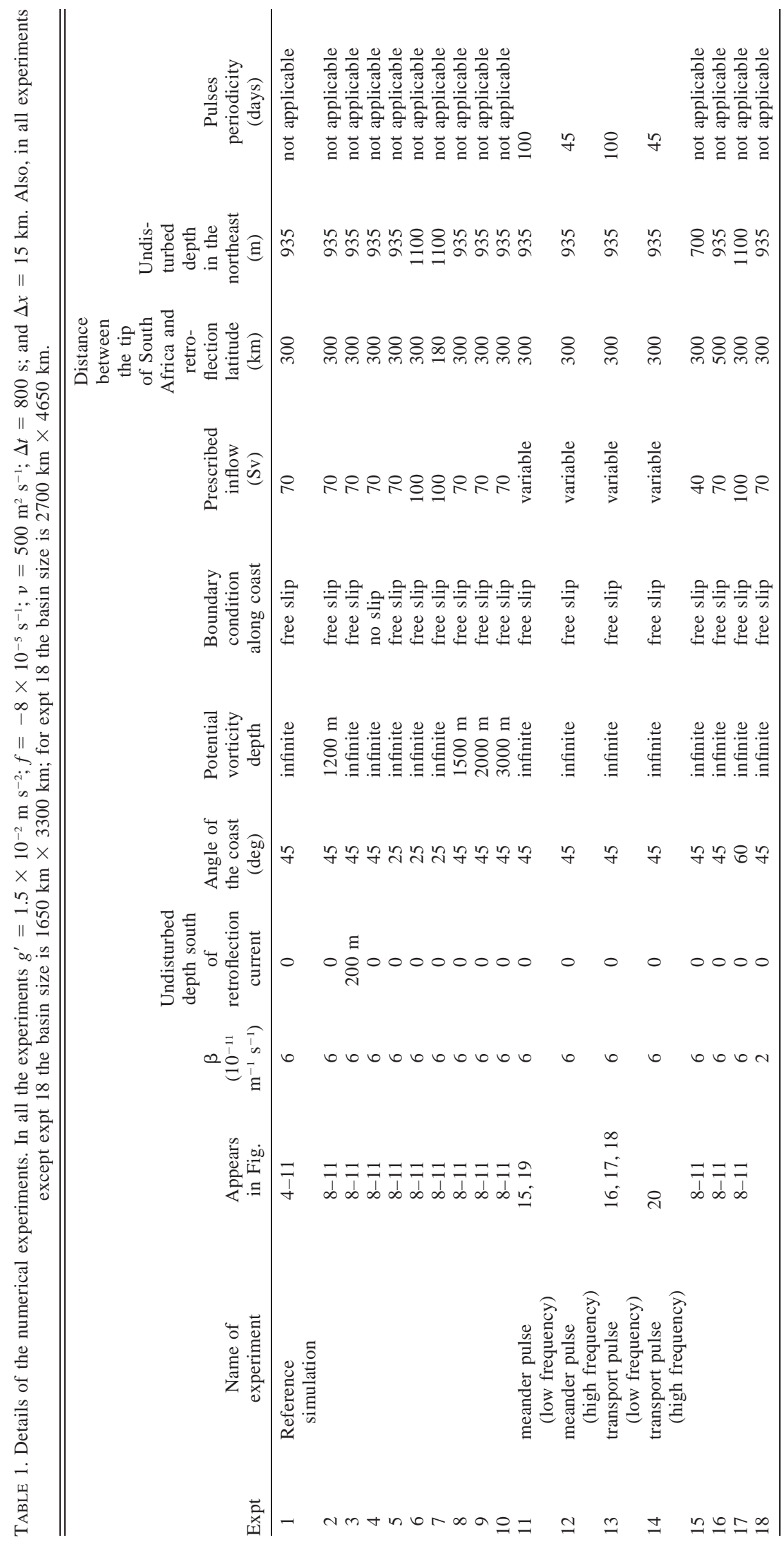


open boundary conditions are satisfactory. In addition, changing the location of the boundary did not alter the behavior of the interior flow indicating that the boundary conditions are adequate. Note that, since the frontal flow does not reach the northern and southern boundaries ED and $\mathrm{CAB}$ (see Fig. 3), it really does not matter what conditions are prescribed there.

A constant uniform potential vorticity inflow parallel to the eastern coast of Africa is prescribed along the northern boundary (section FG, Fig. 3). (Note that the potential vorticity is zero when the potential vorticity depth is infinite.) Such a current has maximum speed along the (slippery) boundary. This upstream speed decays exponentially to zero as one moves a few Rossby radii offshore (which is in agreement with the observations). The initial conditions consist then of a current (geostrophic in the regions where it is rectilinear) that retroflects at the chosen latitude and then flows eastward (Fig. 3). The two regions where the current is rectilinear are connected by circular isolines tangential to the upstream current (at the tip of Africa) and the zonal downstream current. Initially, the current is forced to retroflect by adjusting the upstream depth along the coast in such a way that the upstream transport equals the specified downstream transport; that is, conservation of mass requires the current to retroflect at $t=0$. After these initial conditions are set, the current is free to do whatever the dynamics require it to do. We shall see, however, that, even though the retroflection is no longer forced, the current chooses to maintain the retroflected position.

The experiments were done using the following parameters. The reduced gravity was $g^{\prime}=1.5 \times 10^{-2} \mathrm{~m}$ $\mathrm{s}^{-2}$ and the Coriolis parameter $f_{0}=-8 \times 10^{-5} \mathrm{~s}^{-1}$. The other parameters vary according to Table 1 . The numerical parameters of the model are (i) a time step of $800 \mathrm{~s}$, (ii) a grid step of $15 \mathrm{~km}$ (i.e., three grid points per one Rossby radius), (iii) a grid size of $220 \times 110$ points, and (iv) a Laplacian viscosity coefficient of $\nu=$ $5 \times 10^{-2} \mathrm{~m}^{2} \mathrm{~s}^{-1}$ (which is the lowest we could choose for stability).

\section{b. Reference simulation}

In this first basic experiment (Expt. 1), the angle of the coast $\gamma$ was $45^{\circ}$ and the current retroflected $300 \mathrm{~km}$ south of the tip of Africa. The results are shown in Figs. 4,5 , and 6 . The overall behavior of the flow is as expected, that is, the current flows along the east coast of Africa, retroflects, forms the Agulhas Return Current, and produces rings in the process.

Several points deserve particular attention:

1) The flow, in general, and the ring formation, in particular, are not exactly periodic. Nevertheless, we can define the "periodicity" of the flow to be the average time required for the shedding of a ring.

2) The downstream current is not steady but strongly meanders. The meanders can form eddies to the north

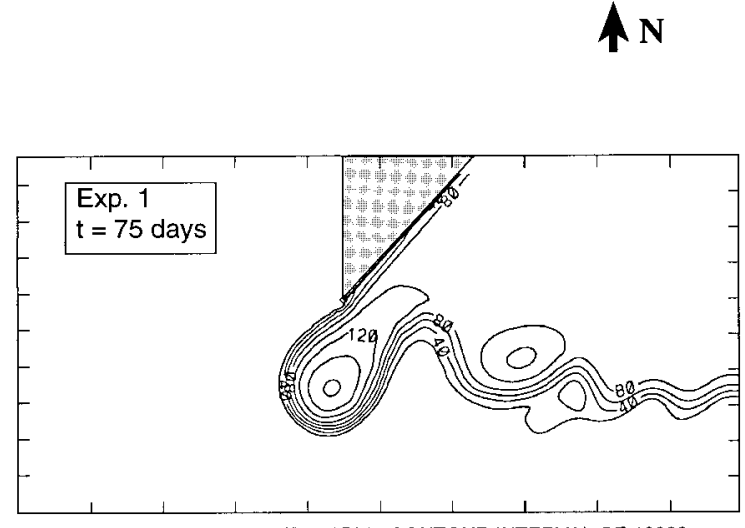

CONTOUR FROM 501.00 TO 90501 . CONTOUR INTERVAL OF 10000

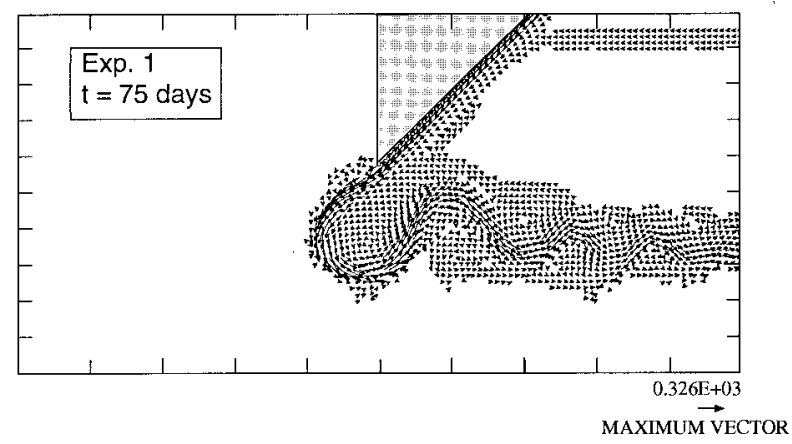

FIG. 4. Depth contours (upper panel) and velocity vectors (lower panel) of the reference simulation (expt 1). As in our analytical calculations, the prescribed inflow has zero potential vorticity. The retroflected current was initialized $300 \mathrm{~km}$ south of the tip of Africa. Note that, by this time, the retroflection loop has prograded southwestward away from the coast (Fig. 3). Velocity vectors are given in centimeters per second; depth contours are given in tens of meters; the basin size is $1650 \mathrm{~km} \times 3300 \mathrm{~km}$.

or to the south (Fig. 6), as observed regularly in nature (e.g., Lutjeharms and Valentine 1988). (Note that, in reality, some of the meanders are due to bottom topography.) Despite these oscillations, however, a measure of the current geostrophy 40 grid points west of the eastern boundary shows that the current is geostrophic within $20 \%$, indicating that the assumption made in the theoretical analysis is reasonable (Fig. 7a). Also, a comparison of the analytical and numerical momemtum fluxes will later show that the assumption is adequate.

3) The Agulhas Return Current maintains its retroflected position despite the fact that it is not forced to do so after its initial formation.

4) The upstream current has fluctuations in its transport (Fig. 7b). These fluctuations are a result of the retroflection process, which influences the upstream conditions through the radiation of Kelvin waves along the coast. Since the inflow is prescribed as steady in our simulations, these fluctuations are com- 


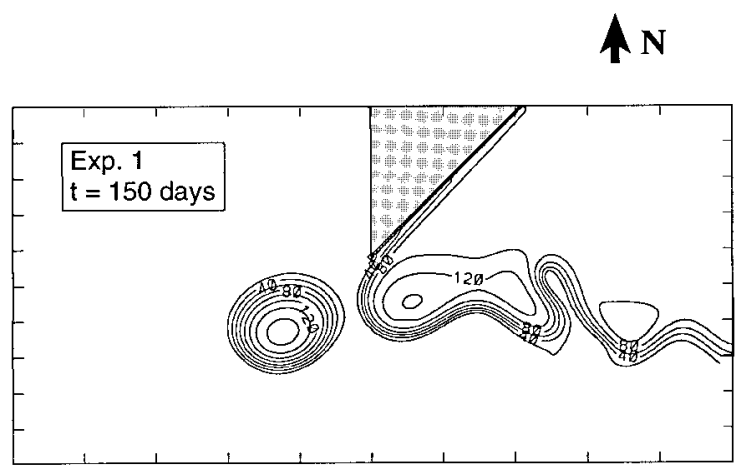

CONTOUR FROM 501.00 TO 90501. CONTOUR INTERVAL OF 10000

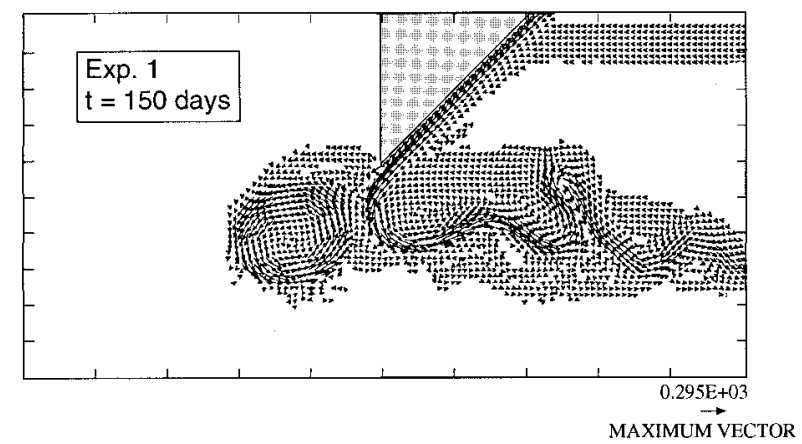

FIG. 5. Same as Fig. 4 but at $t=150$ days (Expt. 1). By now, the retroflecting loop has closed upon itself and a ring has been shed Also, note the "pool" of cold water that is formed by a strong meander in the Agulhas Return Current. As before, velocity vectors are given in centimeters per second and depth contours are given in tens of meters.

pensated for by a weak zonal current flowing along the northern wall. This current can be seen in the lower panels of Figs. 4-6 where the velocity vectors are shown but is too weak to be noticed in the depth contour plots. In the real ocean, those fluctuations would probably travel farther upstream. These fluctuations are not negligible and can change the transport by as much as $35 \mathrm{~Sv}$, which is $50 \%$ of the inflow in the magnified $\beta$ experiment. The resulting averaged volume flux of the inflow is $85.4 \mathrm{~Sv}$. With the regular nonmagnified $\beta$ the change in the transport is no more than $25 \%$. (It is presently unknown whether such fluctuations occur in the real ocean.)

5) Occasionally, eddies formed in the northeastern part of the retroflected current detach, propagate westward and encounter the approaching current. (This can result in a numerical transport "pulse.") By contrast, in nature, these eddies are observed to be advected eastward, implying that these simulated events are probably artificial.

The simulated formation of an Agulhas ring is very similar to what is observed in the ocean. In the retro-
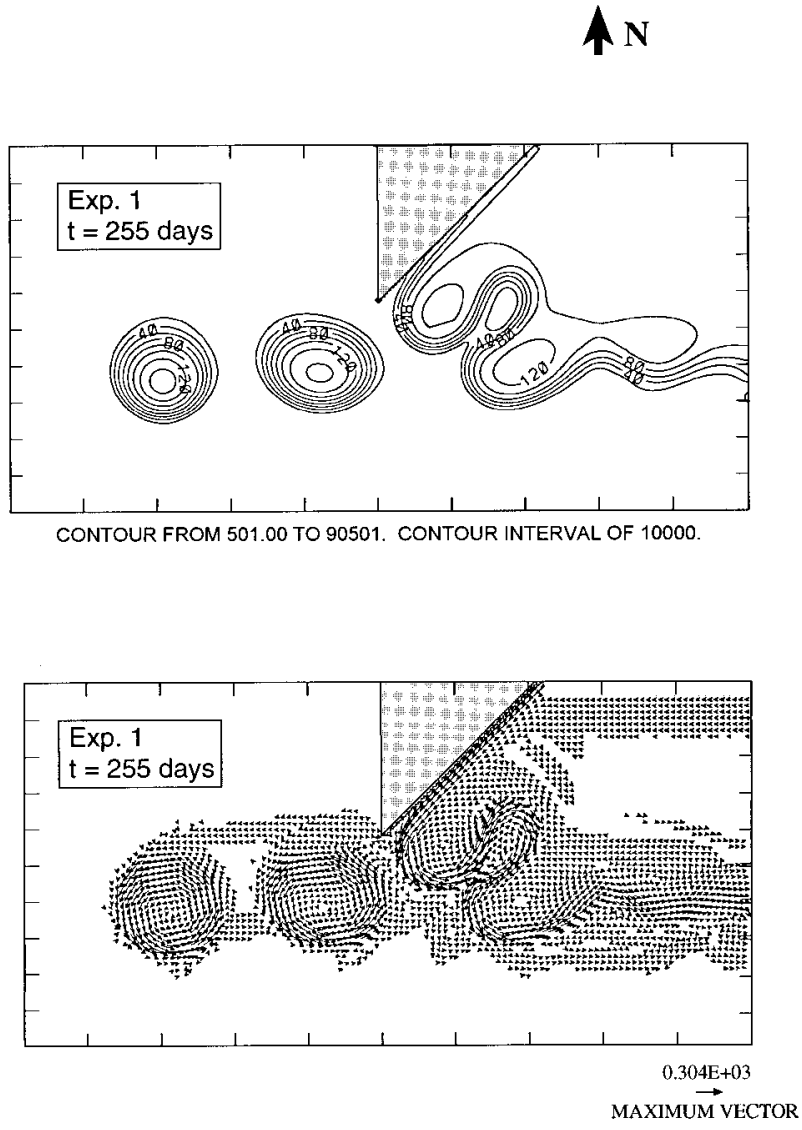

FIG. 6. Same as Fig. 4 but at $t=255$ days (Expt. 1). By this time, a second ring has been shed. Note the upstream retroflection point and (again) the pool of cold water formed by a strong meander in the Agulhas Return Current. Also, note that the two generated Agulhas rings are fairly close to each other indicating that our "kissing" condition (used to close the analytical solution) is not too bad.

flection area, the loop of the current forms a front that moves southwestward along the coast at about $4 \mathrm{~km}$ day $^{-1}$. (In nature, the actual propagation speed is somewhat faster, 7-15 $\mathrm{km} \mathrm{day}^{-1}$.) This causes a narrowing of the northern part of the loop until a ring is formed and is carried westward by $\beta$. As a result, the retroflection point moves to an upstream position, roughly where the loop closed upon itself (Fig. 6). This is also consistent with the observations.

The westward drift of the numerical rings is $6 \mathrm{~km}$ day $^{-1}$, in good agreement with the observed drift speed. Namely, although artificial, the magnified value of $\beta$ gives a reasonable migration rate. However, in the numerical experiments with magnified $\beta$, the periodicity of the rings is roughly 130 days, leading to a relatively large simulated ring volume flux of $17.5 \mathrm{~Sv}$ (20.4\% of the averaged total inflow). Both the numerically simulated periodicity and the simulated eddy mass flux are about twice or three times as large as the observed values (60 days, $5 \mathrm{~Sv}$ ). The experiment with realistic (instead of magnified) $\beta$ (Expt. 18) gives a more reasonable 


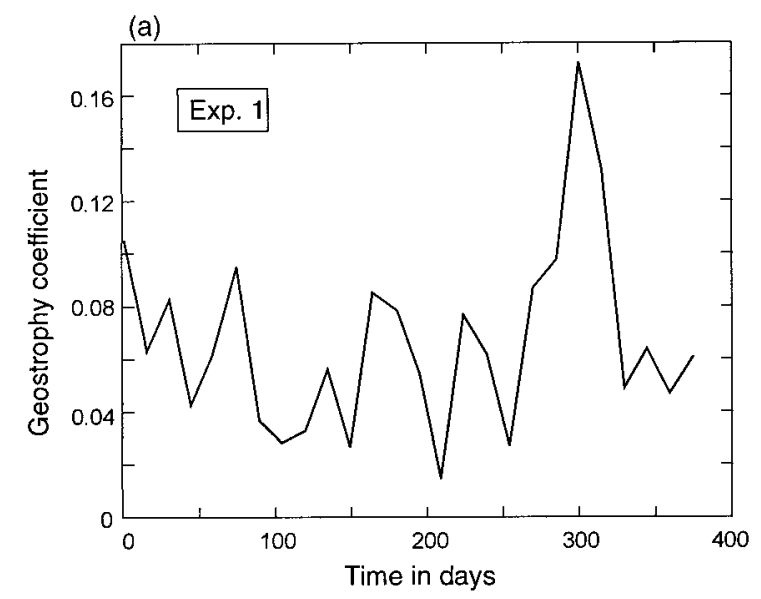

FIG. 7a. The geostrophic coefficient of the downstream current [defined by $\Sigma u^{2}\left|u-u_{g}\right| / \Sigma u^{2}$, where $u$ is the instantaneous speed and $u_{g}$ is the geostrophic speed computed from the depth profile. (Note that the inclusion of $u^{2}$ in the coefficient emphasizes the high speeds rather than the weak flow.)] as a function of time (Expt. 1). This calculation was done over cross-section $\mathrm{B}^{\prime} \mathrm{H}$ (shown in Fig. 3). The figure shows that the downstream deviations from geostrophy and, hence, the deviations from one-dimensionality, are usually less than $20 \%$.

value for the mass flux (about $7 \mathrm{~Sv}$ ) but less reasonable values for both the periodicity and the size. The rings are produced more slowly than in nature, about once every 500 days (instead of once every 90 days or less). Similarly, their radius is $370 \mathrm{~km}$ instead of about 100 $\mathrm{km}$.

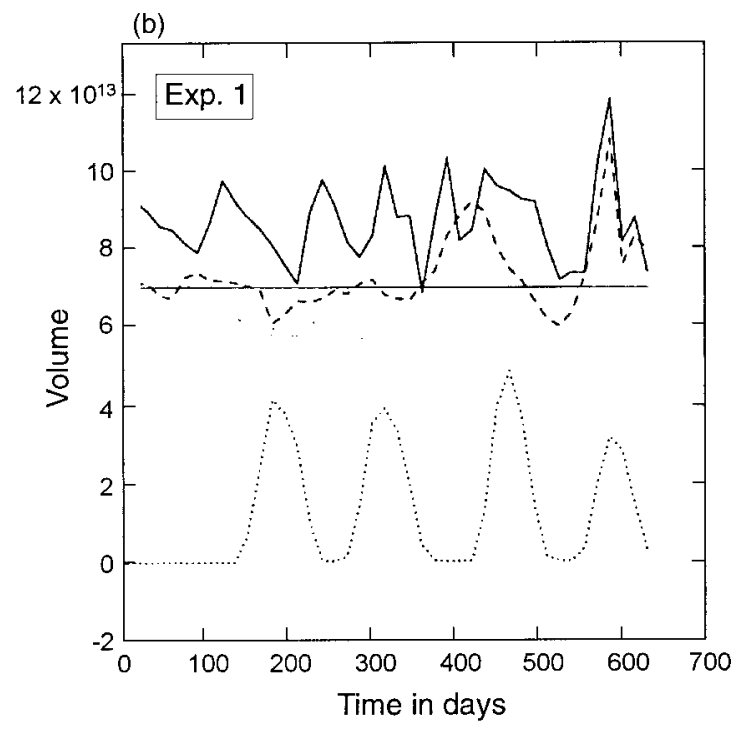

FIG. 7b. The simulated volume fluxes $\left(\mathrm{cm}^{3} \mathrm{~s}^{-1}\right)$ of the prescribed inflow (straight plain line), the adjusted inflow [measured $60 \mathrm{~km}$ downstream of the northern boundary (irregular plain line)], the retroflected current (dashed line), and the rings (dotted line). Note that the formation of rings is fairly periodic, and that both the Agulhas Return current and the inflow experience strong transport fluctuations.

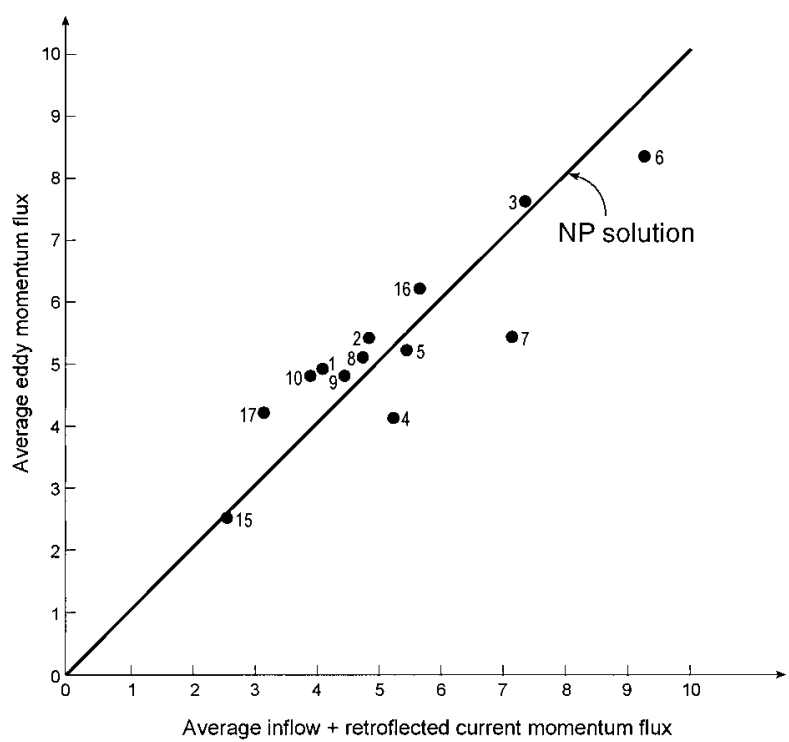

FIG. 8. The simulated eddies momentum flux averaged over three periods $\left[(1 / 3 T) \int_{0}^{3 T} \int\left(h u^{2}-f \psi+g h^{2} / 2\right) d y d t\right.$, where $T$ is the periodicity, $h$ the layer thickness, and $\psi$ the streamfunction defined in the conventional manner] as a function of the combined upstream and downstream momentum fluxes (in $10^{16} \mathrm{~cm}^{4} \mathrm{~s}^{-2}$ ). For each numerical experiment, the measured value of the eddy momentum flux and the measured value of the inflow and outflow momentum flux are plotted, that is, the solid line shows the balance considered in NP's analytical computations and the solid dots are the numerical experiments. [Numerals correspond to the number of the experiment (Table 1)]. Note that, despite the "kissing assumption" made in NP (implying that the eddies touch each other as they move westward), and despite the relatively large value of the expansion parameter $\left[\varepsilon^{1 /}\right.$ $\left.{ }^{6} \equiv\left(\beta R_{d} / f_{0}\right)^{1 / 6} \approx 0.48\right]$, the agreement is very good. This is because the comparison involves two integrations (one in space and one in time), which tend to smooth out the errors.

\section{c. Sensitivity experiments}

Sensitivity experiments were conducted to show how robust the results of the reference simulation are, and how they can possibly be improved (see Table 1 and Figs. 8, 9, 10, and 11). We performed a total of 17 additional experiments, four of which simulate the Natal pulse (and will be discussed later). The experiments were conducted by varying the chosen depths, potential vorticity, and other variables (Table 1). The experiments include simulations with three different inclinations of the coastline $\left(25^{\circ}, 45^{\circ}\right.$, and $\left.60^{\circ}\right)$, five different values of potential vorticity $\left[0,6.67,5.33,4\right.$, and $2.67\left(\times 10^{-8}\right.$ $\left.\mathrm{m}^{-1} \mathrm{~s}^{-1}\right)$ ], four upstream transports $(40 \mathrm{~Sv}, 70 \mathrm{~Sv}, 100$ Sv, and variable), four undisturbed depths $(700 \mathrm{~m}, 935$ $\mathrm{m}, 1000 \mathrm{~m}$, and $1100 \mathrm{~m}$ ), and four with variable transports (the pulse experiments). They also include, one experiment with no-slip along the continent instead of free-slip, one with a finite depth south of the Agulhas Return Current instead of zero depth, which the NP theory requires, and one with $\beta$ of $2 \times 10^{-11} \mathrm{~m}^{-1} \mathrm{~s}^{-1}$ instead of $6 \times 10^{-11} \mathrm{~m}^{-1} \mathrm{~s}^{-1}$. For most of the experiments we chose a magnified value for $\beta$ of $6 \times 10^{-11}$ 


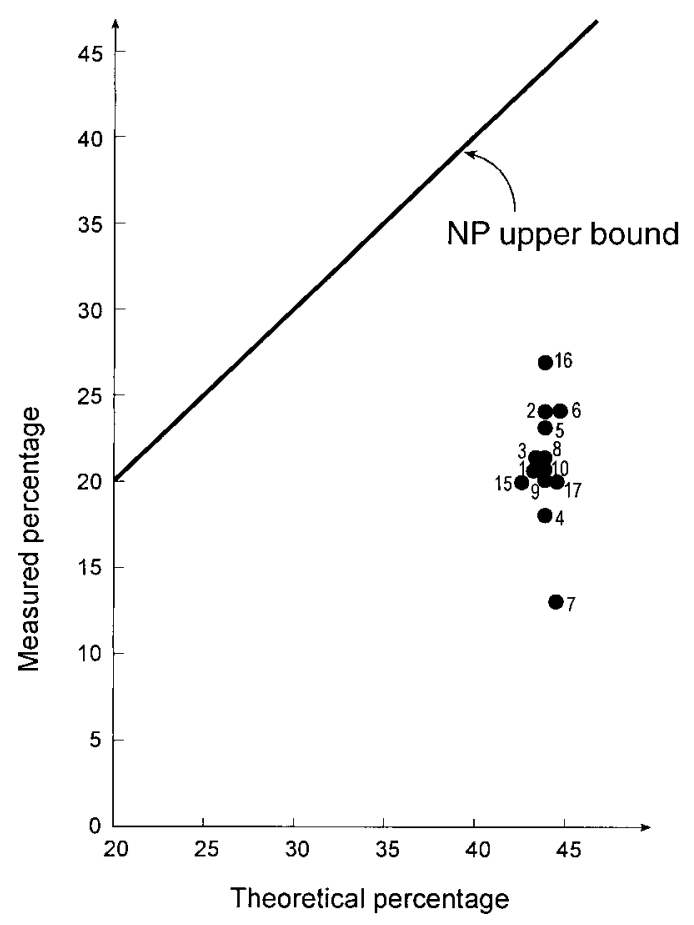

FIG. 9. The measured simulated eddy mass flux relative to the main current flux (percentage) versus the theoretically calculated eddy mass flux (percentage). For each numerical experiment, the numerical value is given on the vertical axis and the theoretical value on the horizontal axis. Hence, the solid line is the (NP) theoretical upper bound, that is, the dots must lie below the line if the analytical bound found by NP is valid. Note that the inclination of the coastline is absent from the theoretical calculations and that the theoretical calculations are for relative vorticity of $-0.2 f$ at the center of the eddies. The difference between the upper bound and the numerical values are due to the "kissing assumption" and the relatively large value of the expansion parameter (0.48).

$\mathrm{m}^{-1} \mathrm{~s}^{-1}$; such a magnified value accelerates the detachment of the rings and makes our runs more economical.

We changed only one parameter at a time, keeping the others fixed. We began by varying the potential vorticity of the current and noting that changing the zero potential vorticity of the inflow to a finite potential vorticity (expt 2) does not alter the overall behavior of the flow. When the potential vorticity depth $H_{p}$ is 1.2 times the undisturbed depth in the northeast, the periodicity becomes 150 days and the volume flux of the rings is 17.2 Sv, slightly different from the zero potential vorticity experiment (130 days and 17.5 Sv). The influence of the potential vorticity was also tested in experiments 8,9 , and 10, which confirm the (weak) tendency of a decrease in the potential vorticity depth to increase the periodicity and ring volume flux.

Setting the depth in the south to be $200 \mathrm{~m}$ (expt 3) instead of zero also leads to a behavior qualitatively similar to that of the reference simulation. The resulting periodicity is 100 days and the ring volume flux 15.2 Sv. These results are much closer to the observations, probably because the actual depth in the south is not

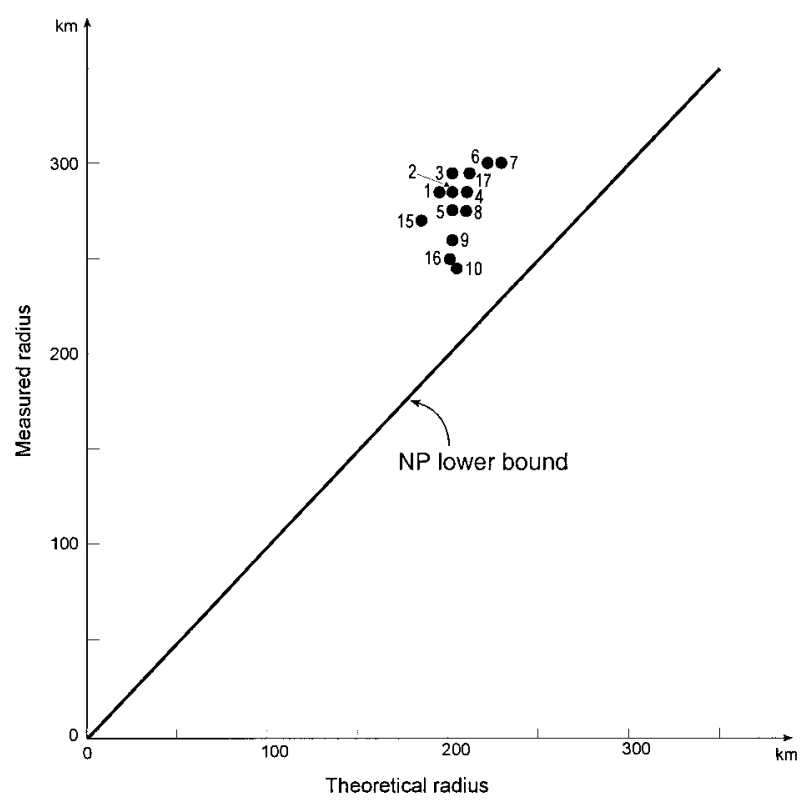

FIG. 10. The simulated ring's radius (in km) versus the theoretically predicted radius. As before, for each numerical experiment the measured radius is given on the vertical axis and the theoretically computed value is given on the horizontal axis. Hence, the solid line represents the NP lower bound, that is, the dots must lie above the line if the bound found by NP is correct. Note that, as before, the diffrences between the numerically simulated size and the lower bound are due to (a) the so-called kissing assumption made in NP's calculations (implying that the rings are touching each other) and (b) the expansion parameter $\left[\varepsilon^{1 / 6} \equiv\left(\beta R_{d} / f_{0}\right)^{1 / 6}\right]$, which is relatively large $(0.48)$. [Also, note that the simulated ring's radius was determined by extrapolating the steep gradient of the bell-shaped thickness profile toward the free surface and finding the (closed) contour along which it strikes the free surface.]

zero but rather is a few hundred meters. Using no-slip boundary conditions along the African coast (expt 4) instead of slip conditions does not lead to qualitative changes either. The periodicity of ring shedding is unchanged at 130 days and the ring volume flux is now 14.9 Sv, which is $18 \%$ of the inflow and is closer to the observations. (The volume flux of the total inflow is reduced from $85.4 \mathrm{~Sv}$ to $82 \mathrm{~Sv}$ when using the no-slip boundary conditions.)

Repeating the reference simulation, but giving a smaller value to the angle of the coast $\left(25^{\circ}\right.$ instead of $45^{\circ}$, see details for expt 5 in Table 1$)$ results in a periodicity of 110 days (instead of 130 days) and a ring volume flux of $19 \mathrm{~Sv}$ (instead of $17.5 \mathrm{~Sv}$ ). However, in experiment 17 , a larger angle leads to a smaller rather than larger periodicity, so that the influence of the angle variations is not clear. With an angle $\gamma=25^{\circ}$, but with an inflow increased to $100 \mathrm{~Sv}$ (expt 6), we find a decreased periodicity of 90 days and an increased eddy volume flux of $24 \%$ (compared to $23 \%$ in expt 5 ). The sensitivity of the analytical solution to the upstream volume flux is confirmed by experiment 15 , which includes a reduction of the upstream mass flux to $40 \mathrm{~Sv}$. (Note that expt 15 is to be compared to expt 1 because 


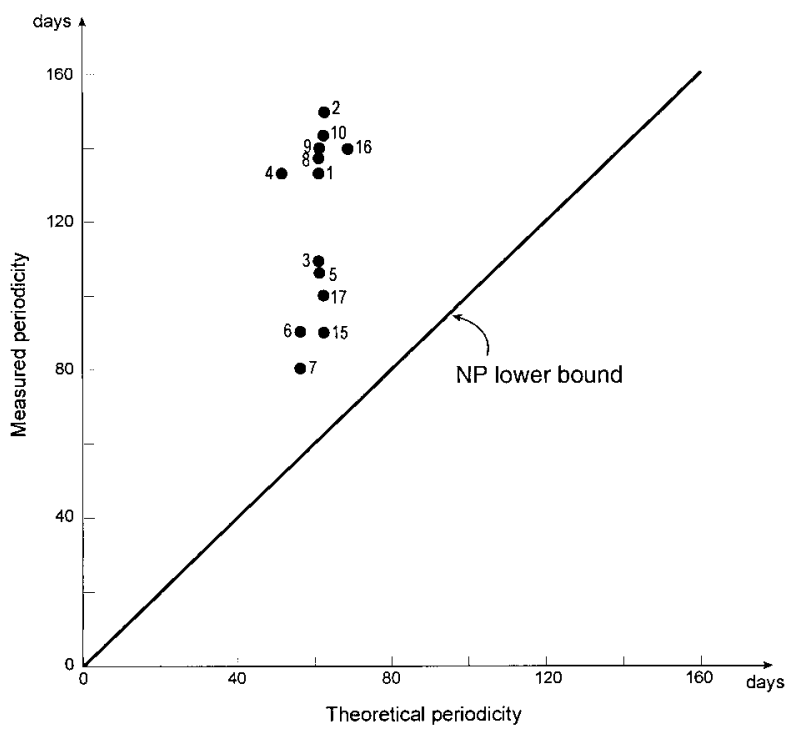

FIG. 11. The simulated ring periodicity (in days) versus the theoretically predicted periodicity. Again, as before, for each numerical experiment the measured value is given on the vertical axis and the theoretical values on the horizontal axis. The solid line represents the NP lower bound in the sense that all the dots must lie above the line if the NP results are valid. Recall that, as before, the differences between the numerically simulated periodicity and the theoretically predicted periodicity is due to (a) the so-called kissing assumption made in NP's calculations and (b) that the NP expansion parameter is relatively large $(0.48)$.

both involve an angle of $45^{\circ}$ ). This resulted in an increased periodicity of 150 days and a decreased ring volume flux of $19 \%$ (instead of $20 \%$ ). With the retroflected current set $180 \mathrm{~km}$ south of the tip (expt 7) instead of $300 \mathrm{~km}$, the periodicity is less defined and has an average of 80 days. The eddy volume flux is reduced to $19 \mathrm{~Sv}$. The loop that is formed between the approaching and retroflected currents can now be closed much faster (because the currents are initially closer) so that the rings are smaller and are produced faster. This is confirmed by experiment 16 (to be compared to expt 1) in which the distance was set to $500 \mathrm{~km}$.

We can say (on the basis of the results shown in Figs. 8-11) that, within the range of parameters surveyed, the overall behavior of the flow is not drastically affected by the potential vorticity, the depth in the south, the free slip/no slip boundary conditions at the coast, the angle of the coast, the volume flux of the approaching current, and the latitude of the retroflected current. However, these parameters modify the periodicity and the ring volume flux.

The best agreement between the NP analytical solution and the numerical simulation is in the momentumflux balance (Fig. 8). This agreement is very good despite the various approximations (such as the "kissing assumption") because the comparison is between properties integrated over both space and time. Such integrations tend to smooth out the errors. The comparison of the analytical and numerical mass flux (Fig. 9) as well as the comparisons of the eddies' radius and periodicity (Figs. 10 and 11) are in agreement with our upper and lower bound considerations. Here, the difference between the theory and the experiments reflects the kissing assumption and the relatively large value of the expansion parameter $\varepsilon^{1 / 6}(\approx 0.48)$.

Before proceeding and discussing the relationship between our numerical results for the Natal pulse, it is appropriate to comment again on the relationship between our simulated eddy mass flux, the simulated eddy periodicity, and the simulated eddy radius to the corresponding values observed in the ocean. The simulated eddy mass flux in the experiments with magnified $\beta$ (Expts. 1-17) is, on average, 20\% of the simulated upstream transport (Fig. 9), which, for a simulated upstream transport of $70 \mathrm{~Sv}$, gives about $14 \mathrm{~Sv}$. Similarly, the average simulated periodicity with magnified $\beta$ is about 110 days (Fig. 10) and the average simulated size is about $270 \mathrm{~km}$. With realistic $\beta$ (expt 18) the eddy mass flux reduces to about $7 \mathrm{~Sv}$ but the periodicity increases to 500 days and the size to $370 \mathrm{~km}$. Since the deformation radius in our model is similar to the oceanic value $(\approx 48 \mathrm{~km})$ and so is the Coriolis parameter, we can directly compare the above results to the observed values. The upper bound for the eddy mass flux (7 Sv) is fairly close to the observed flux $(\sim 5 \mathrm{~Sv})$ but the remaining variables (periodicity and size) are two to three times larger than the observed values. Nevertheless, we believe that our very simple model captures the fundamental dynamics of ring formation.

\section{d. Relationship to Chassignet and Boudra's (1988) and Boudra and Chassignet's (1988) results}

Using numerical simulations in a three-layer isopycnic model, Boudra and Chassignet (1988) and Chassignet and Boudra (1988) suggested that the formation of Agulhas rings was due to a mixed barotropic-baroclinic instability. Since our integrated approach does not give any information about the detailed local mechanism responsible for the generation of rings, it is impossible for us to say what the exact mechanism is. However, our model suggests that it is not appropriate to speak here of classical instability because there is no known steady state that is breaking down. Boudra and Chassignet's (1988) and Chassignet and Boudra's (1988) sensitivity analysis showed that decreasing the angle of the coast lead to an increase in the production of rings. Our related numerical experiments are inconclusive. While experiment 5 shows indeed a shorter periodicity than experiment 15 (which has a larger angle), experiments 6 and 17 show the same periodicity even though the angles in the two experiments are quite different (see Table 1 and Fig. 10). Also, Boudra and Chassignet (1988) and Chassignet and Boudra (1988) found that increasing the inertia reduces the production of rings because their jet can retroflect more easily. Our results show, on the other hand, that changing the inertia (via 


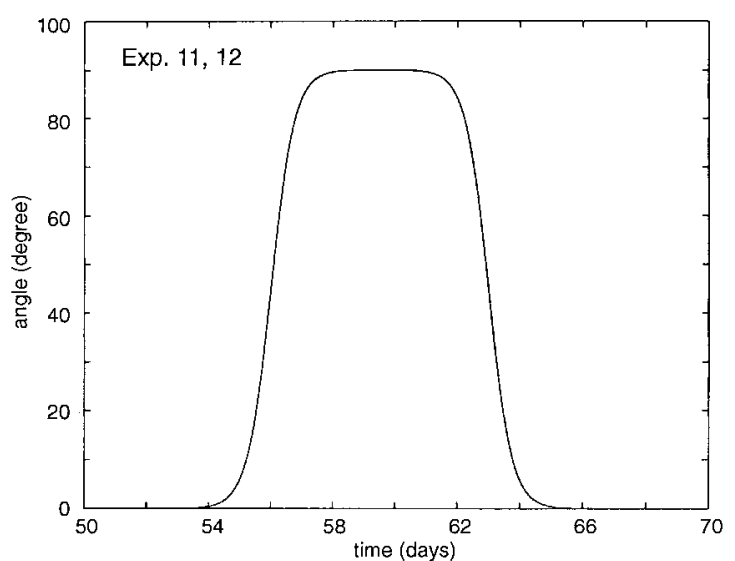

FIG. 12. The angle (measured counterclockwise from the coast to the prescribed velocity vector) corresponding to the meander pulse.

changing the potential vorticity depth) has little effect on the periodicity (see expt 1 shown in Figs. 4-7 and expts 8, 9, and 10 shown in Fig. 10). Given the fundamental differences between the Boudra and Chassignet (1988) and Chassignet and Boudra (1988) model (a closed basin three-layer model driven by wind) and our model (an open basin 11/2-layer model driven only by inflow and outflow specifications), it is impossible to pinpoint the processes responsible for the differences in ring production.

\section{Simulating the Natal pulse}

We used two different models to examine the role of the Natal pulse (expts 11-14) and conducted four pulse experiments. First, we used a "meander pulse," which is a meander generated by orienting the velocity vectors of the prescribed inflow normal to the coast during a finite amount of time (expts 11, 12). Second, we used a "transport pulse," where the velocity of the prescribed inflow is temporarily increased so that the transport is

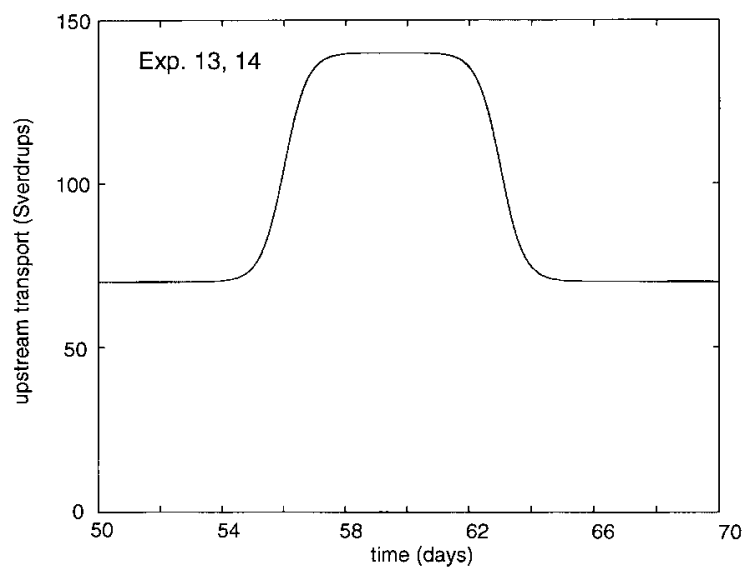

FIG. 13. Evolution of the prescribed inflow during a transport pulse.
NO PULSE (Exp. $1, t=75$ days)

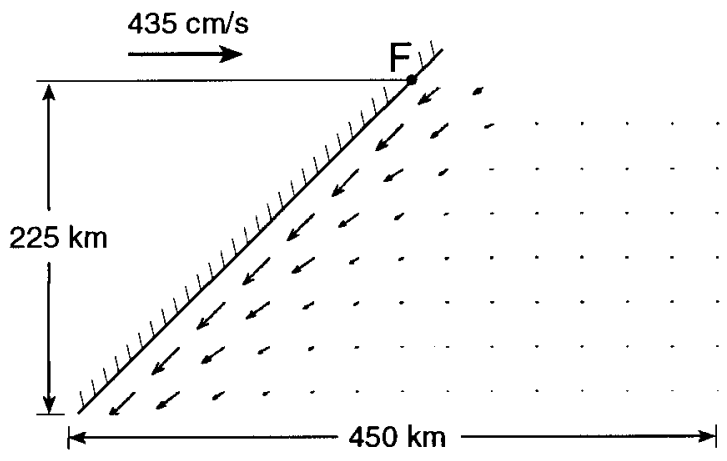

GENERATION OF A MEANDER PULSE

(Exp. $11, t=75$ days)

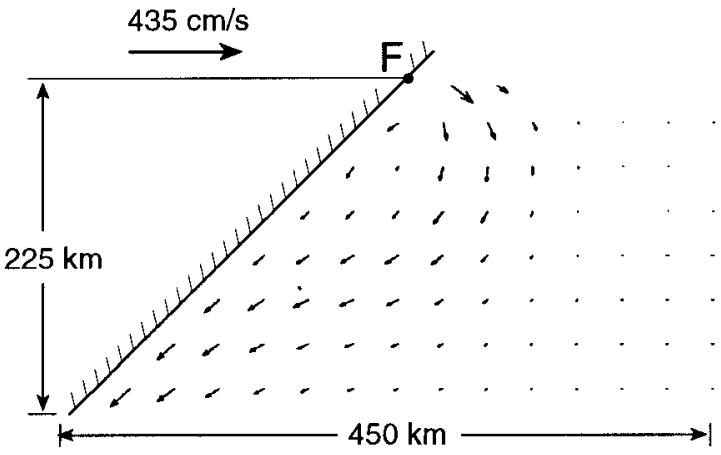

GENERATION OF A TRANSPORT PULSE (Exp. $13, t=75$ days)

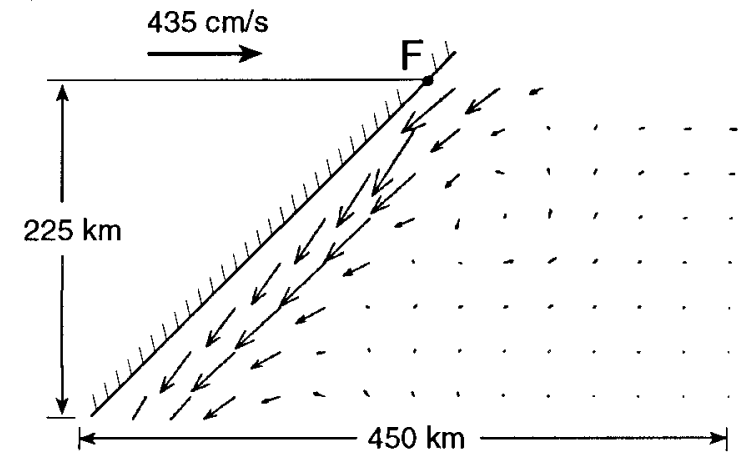

FIG. 14. The velocity vectors of the upstream reference simulation (upper panel), the meander pulse (central panel), and the transport pulse (lower panel). Note that all are shown for day 75 . The position of point $\mathrm{F}$ relative to the African continent is shown in Fig. 3 .

temporarily doubled (expts 13 and 14). In two out of the four pulse numerical experiments, the pulses were prescribed five times at a 100 day interval, each pulse lasting for 7 days (expts 11 and 13). The remaining two pulse experiments (expts 12 and 14) contained a 45-day interval instead of 100 days. All of these values are in qualitative agreement with oceanic values. 


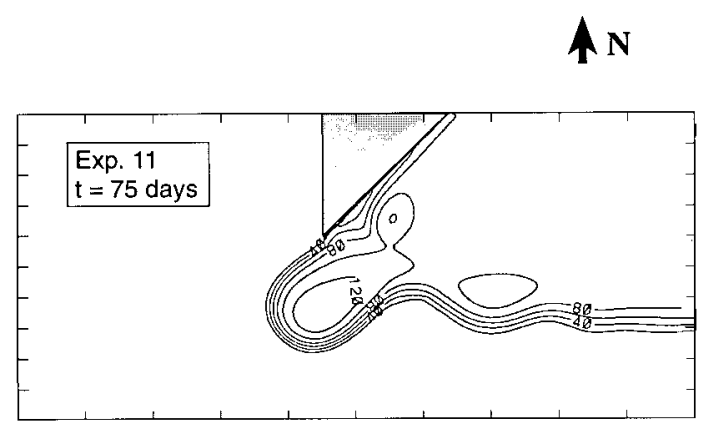

CONTOUR FROM 501.00 TO 90501. CONTOUR INTERVAL OF 10000.

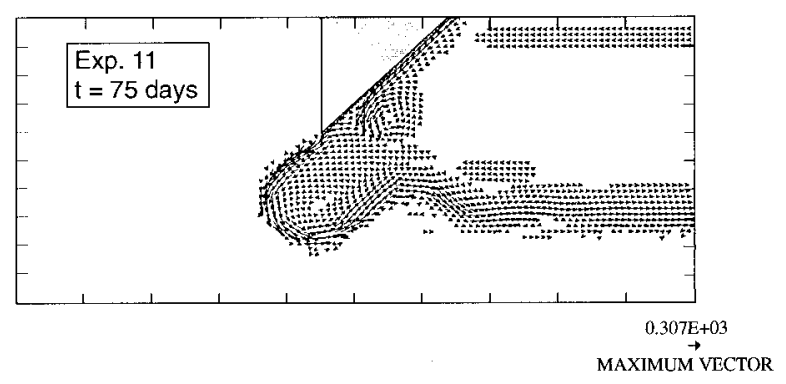

FIG. 15. As in Fig. 4 but with a Natal pulse simulated as a meander in the prescribed inflow every 100 days (expt 11). This results in a small eddy, which propagates downstream along the coast and can sometimes close the retroflecting loop. Basin size: $1500 \mathrm{~km} \times 3300$ $\mathrm{km}$. As before, velocity vectors are given in centimeters per second and depth contours are given in tens of meters.

The way that the pulses were simulated is shown in Figs. 12, 13, and 14. The meander pulse was generated by aligning the flow along the wall at a (varying) angle for a period of roughly 10 days (Fig. 12). The transport pulse was generated by gradually increasing the transport (to twice its original value) and then decreasing it over a period of roughly 10 days (Fig. 13). A relatively short adjustment $[O(1)$ day] takes place immediately after the pulses are generated. As expected, once this adjustment is completed (at, say, 10 days after their generation), there are no discontinuities in the flow field (Fig. 14).

We found that a meander pulse generates a "coastal" eddy that propagates downstream along the African coast at a speed of $40 \mathrm{~cm} \mathrm{~s}^{-1}$ (see Fig. 15), whereas a similar transport pulse results in two eddies: the first one stronger than the meander eddy and the second one weaker (see Figs. 16 and 17). These two eddies propagate downstream at roughly $50 \mathrm{~cm} \mathrm{~s}^{-1}$. They are separated by a distance of $300 \mathrm{~km}$, indicating that they were produced at 6.9 days interval, which is the duration of the pulse; that is, the first eddy was produced when the volume flux increased, and the second one when it decreased back to its initial value 7 days later. The pres-

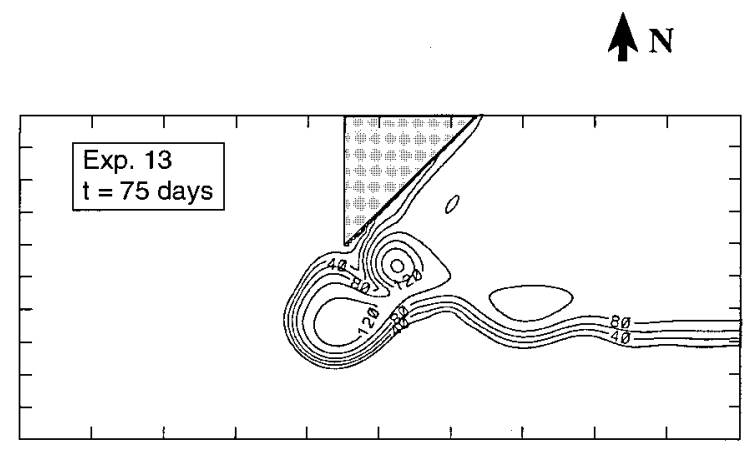

CONTOUR FROM 501.00 TO 90501. CONTOUR INTERVAL OF 10000.

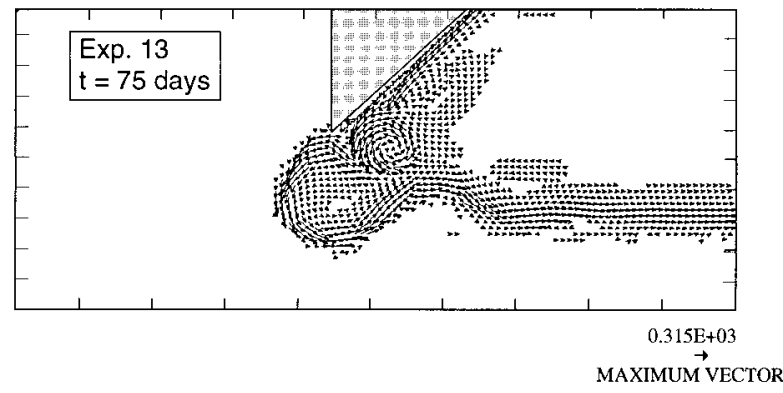

FIG. 16. Numerical experiment with a low frequency Natal pulse simulated as a 7-day doubling of the prescribed inflow transport every 100 days (expt 13). This results in two eddies propagating downstream along the coast. They carry strong enough inertia to push an Agulhas ring westward. Basin size: $1500 \mathrm{~km} \times 3300 \mathrm{~km}$. Again, velocity vectors are given in centimeters per second and depth contours are given in tens of meters.

ence of the two eddies is not in very good agreement with actual Natal pulses (which propagate at about 20 $\mathrm{cm} \mathrm{s}^{-1}$ ). However, the presence of eddies at the seaward side of the Agulhas Current during the passage of a pulse has, on occasion, been inferred from satellite data (Lutjeharms and Roberts 1988; Gründlingh 1996). Note that our numerical pulses initial length scales are 130 $\mathrm{km}$ (meander) and $240 \mathrm{~km}$ (transport). The simulated length scale near the tip of Africa is larger, about 250 $\mathrm{km}$ for the meander pulse and $400 \mathrm{~km}$ for the transport pulse. Both are comparable to the observed values of 200-300 km near Port Elizabeth (Lutjeharms and Roberts 1988).

The impact of the low frequency pulses on the production of Agulhas rings is as follows. A transport pulse always ends up in the shedding of an Agulhas ring (as can be seen in Fig. 18), whereas a meander does not necessarily do so (Fig. 19). Namely, the transport pulses modify the periodicity of ring generation (which adjusts to the periodicity of the pulses), whereas the meander pulses are not able to do so. This can be interpreted as follows. A transport pulse generates inertia that can 

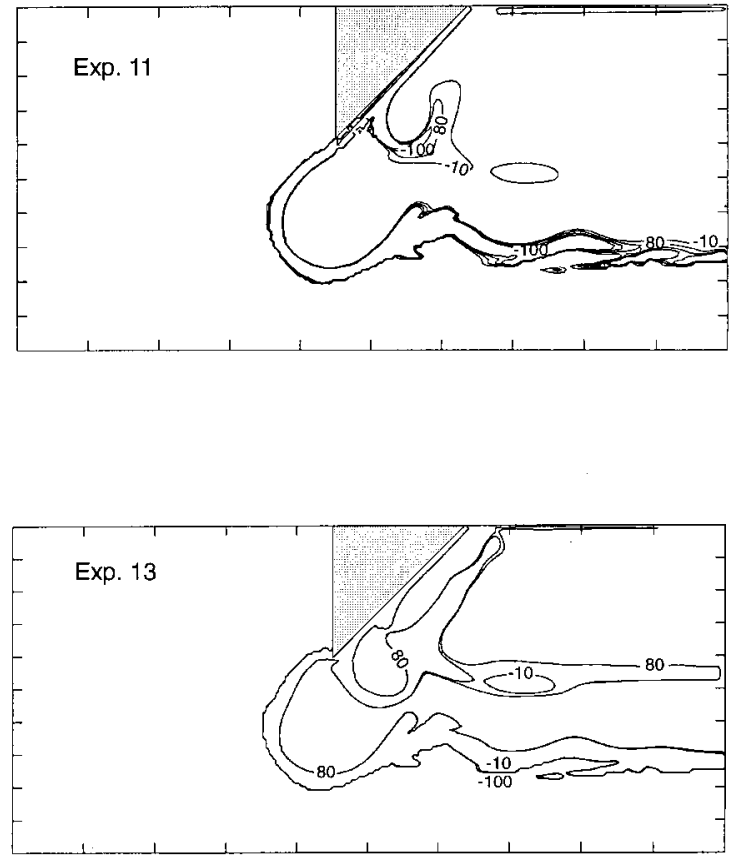

FIG. 17. Relative vorticity at $t=75$ days for a low-frequency meander pulse in units of $10^{-7} \mathrm{~s}^{-1}$ (upper panel). Relative vorticity at $t=75$ days for a low-frequency transport pulse in units of $10^{-7}$ $\mathrm{s}^{-1}$ (lower panel).

"push" the front in the retroflecting area downstream, forcing the loop to close upon itself and the ring to detach. On the other hand, a meander pulse can generate a ring only if it reaches the retroflection area when the loop between the approaching and retroflected current is already almost closed; the meander can then terminate the closure.

The low-frequency transport pulses result in an increased ring volume flux to the detriment of the downstream current. For the low-frequency transport pulse experiment, the ring volume flux represents $22 \%$ of the inflow, compared to $19 \%$ in the no-pulse experiment. On the other hand, for the low-frequency meander experiment, the ring volume flux is only $19.4 \%$ of the inflow showing that it is not much different from the no-meander case.

In a high-frequency experiment, a transport pulse was prescribed every 45 days (expt 14 and Fig. 20). In this case, the periodicity of Agulhas rings production cannot adjust to the relatively short periodicity of the pulses and, consequently, the resulting flow has quite a disturbed, irregular behavior. The same can be said of the high-frequency meander experiment (expt 12).

\section{Summary and conclusions}

Our analysis verifies Nof and Pichevin's (1996) analytical model which shows that, without the production of rings, the flow force associated with the Agulhas Return Current would not be balanced (Fig. 2). The
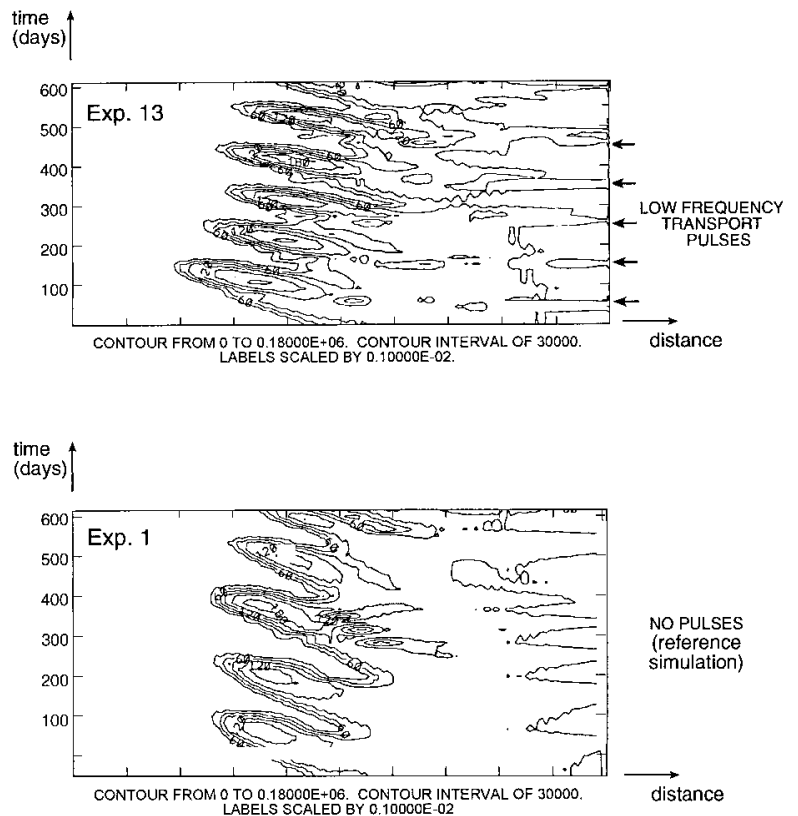

FIG. 18. Two diagrams showing the thickness $h$ in centimeters along the eastern coast as a function of the distance along the coast [measured from the intersection of the virtual continuation of the eastern coast of Africa with the southern wall (point A, Fig. 3)] and time. The upper panel corresponds to the low frequency "transport pulse" simulation, whereas the lower panel is the reference simulation. Each leftward indentation is caused by a southwestward progradation of the retroflection loop, which results in the production of a ring [i.e., rings are produced in both situations (with and without pulses)]. Pulses are shown with short thick arrows on the right-hand side of the upper panel. They were produced every 100 days from day 55. Due to the pulses, the number of rings produced from day zero to day 500 increased from 4 to 5. Each pulse ends up in an Agulhas ring. Contours are given in centimeters.

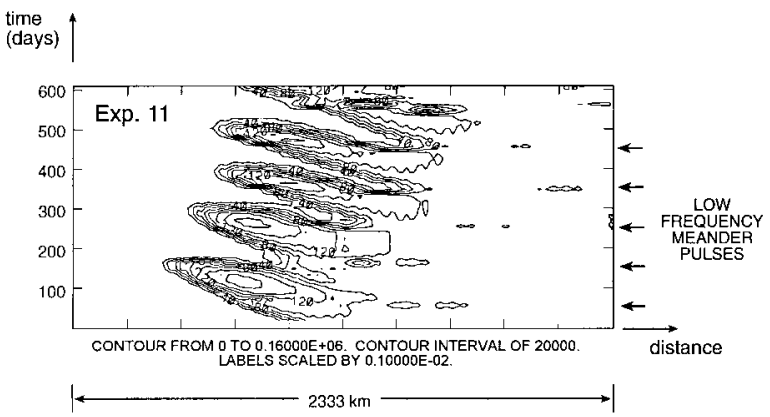

FIG. 19. Same as in Fig. 18, but for the low-frequency meander pulse simulation (expt 11). As with the low-frequency transport pulses, the low-frequency meanders were also produced every 100 days from day 55. In contrast to the transport pulses, however, the number of produced rings has not increased and each meander does not necessarily end up in the production of an Agulhas ring. In other words, there is no clear difference between the no-pulse case (Fig. 18, lower panel) and the present pulse case. Contours are given in centimeters. 


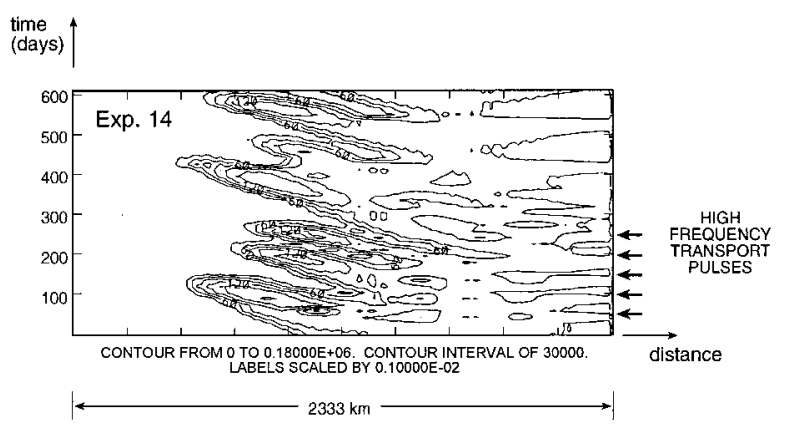

FIG. 20. Same as in Fig. 19 but for a high-frequency transport pulse produced every 45 days (from day 50) instead of a low-frequency pulse produced every 100 days (expt 4). Here, the frequency of the imposed pulses is much greater than the natural rings formation frequency. As a result, the flow cannot adjust to the frequency of the pulses and, consequently, each pulse does not end up in the production of an Agulhas ring. Namely, the flow is less organized than that of the no-pulse case (Fig. 18, lower panel) and there is no obvious correlation between the pulses and the production of rings.

production of rings is therefore intrinsically necessary and is not the result of any other factor such as transport fluctuations, boundary conditions, or instabilities. Using Nof and Pichevin's (1996) theoretical results, we were able to calculate reasonable values for the size and periodicity of the rings. Our reference numerical simulation (Figs. 4-7) together with 13 sensitivity experiments (Figs. 8-11), have confirmed the theoretical analysis. All of our numerical experiments (Table 1) exhibited a similar behavior in terms of the rings momentum flux (Fig. 8), mass flux (Fig. 9), radius (Fig. 10), and periodicity (Fig. 11). Regardless of the particular set of parameters of each experiment, the numerical results were always comparable to the analytical predictions, though some variables (e.g., momentum flux) showed better agreement than others (e.g., periodicity).

As a by-product of our investigation, the influence of the Natal pulse on ring generation was also examined numerically. With the aid of four additional numerical experiments, it was shown that a transport pulse (Fig. 16) can result in the shedding of a ring. Specifically, a transport pulse can accelerate the process of ring shedding, but it does not create it (Figs. 19-20). It was also shown that transport pulses occurring too frequently cannot all result in a ring generation because the flow cannot adjust to a frequency that is too high (Fig. 20). Natal pulses simulated as meanders rather than transport pulses showed far less impact on the production of rings (e.g., see Fig. 19).

Before completing our discussion it should be pointed out that this is a process-oriented study that primarily aims at shedding light on the physical processes responsible for the production of Agulhas rings. That the results are comparable to observations gives strength to the theory, but further and more detailed numerical experiments are necessary to obtain a thorough understanding of the processes in question. For instance, to- pographic features can absorb some of the forces taken into account in our calculation.

Acknowledgments. This study was supported by the National Science Foundation (NSF) under Contracts OCE 9633655 and OCE 9503816, National Aeronautics and Space Administration Grants NAGW 4883 and NAG5-4813, and Office of Naval Research Grant N00014-96-1-0541. T. Pichevin was funded by Service Hydrographique et Océanographique de la Marine (SHOM).

\section{APPENDIX}

\section{List of Symbols}

$f \quad$ Coriolis parameter $\left(f_{0}+\beta y\right)$

$g^{\prime} \quad$ reduced gravity $\left(g^{\prime}=g \Delta \rho / \rho\right)$

$M$ momentum flux of the Agulhas Return Current

$Q_{e}$ eddy mass flux

$R$ radius of the eddies

$R_{d}$ Rossby radius, $\left(g^{\prime} H\right)^{1 / 2} / f_{0}$

$T$ periodicity

$u \quad$ zonal speed

$\alpha$ a measure of the distance between the centers of two consecutive eddies

$\beta$ linear variation of the Coriolis parameter with latitude

$\Delta \rho$ density difference between the layers

$\varepsilon \quad$ small parameter equal to $\beta R_{d} / f_{0}$

$\gamma$ coastline tilt

$\rho$ density

$\nu \quad$ Laplacian viscosity coefficient

\section{REFERENCES}

Bang, N. D., 1970: Dynamic interpretations of a detailed surface temperature chart of the Agulhas Current retroflection and fragmentation area. South Afr. Geogr. J., 52, 67-76.

Bennett, S. L., 1988: Where three oceans meet: The Agulhas retroflection region. Ph.D. thesis, Massachusetts Institute of Technology/Woods Hole Oceanic Institute, WHOI-88-51, xxvii + $367 \mathrm{pp}$.

Bleck, R., and D. Boudra, 1986: Wind-driven spin-up in eddy-resolving ocean models formulated in isopycnic and isobaric coordinates. J. Geophys. Res., 91, 7611-7621.

Boudra, D. B., and W. P. M. de Ruijter, 1986: On the wind-driven circulation of the South Atlantic-Indian Ocean: II. Experiments using a multi-layer numerical model. Deep-Sea Res., 33, 448482.

— , and E. P. Chassignet, 1988: Dynamics of Agulhas retroflection and ring formation in a numerical model. Part I: The vorticity balance. J. Phys. Oceanogr., 18, 280-303.

Byrne, D. A., A. L. Gordon, and W. F. Haxby, 1995. Agulhas eddies: A synoptic view using GEOSAT ERM data. J. Phys. Oceanogr., 25, 902-917.

Chassignet, E. P., and D. B. Boudra, 1988: Dynamics of Agulhas retroflection and ring formation in a numerical model. Part II: Energetics and ring formation. J. Phys. Oceanogr., 18, 304-319.

de Ruijter, W. P. M., 1982: Asymptotic analysis of the Agulhas and Brazil Current systems. J. Phys. Oceanogr., 12, 361-373.

, and D. B. Boudra, 1985: The wind-driven circulation in the 
South Atlantic-Indian Ocean-I. Numerical experiments in a one-layer model. Deep-Sea Res., 32, 557-574.

Dewar, W. K., and C. Gailliard, 1994: The dynamics of barotropically dominated rings. J. Phys. Oceanogr., 24, 5-29.

Dietrich, G., 1935: Veroeff. Int. Komm. Meer, 27.

Duncan, C. P., 1968: An eddy in the subtropical convergence southwest of South Africa. J. Geophys. Res., 73, 531-534.

—, and S. G. Schladow, 1981: World surface currents from ship's drift observations. Int. Hydrogr. Rev., 58, 101-112.

Duncombe Rae, C. M., 1991: Agulhas retroflection rings in the South Atlantic Ocean: An overview. South Afr. J. Mar. Sci., 11, 327 344.

Feron, R. C. V., W. P. M. De Ruijter, and D. Oskam, 1992: Ring shedding in the Agulhas Current system. J. Geophys. Res., 97, 9467-9478.

Flierl, G., 1979: A simple model of the structure of warm and coldcore rings. J. Geophys. Res., 84, 78-85.

Goni, G. J., S. L. Garzoli, A. J. Roubicek, D. B. Olson, and O. B. Brown, 1997: Agulhas ring dynamics from TOPEX/POSEIDON satellite altimeter data. J. Mar. Res., 55, 861-883.

Gordon, A. L., 1985: Indian-Atlantic transfer of thermocline water at the Agulhas retroflection. Science, 227, 1030-1033.

- 1986: Inter-ocean exchange of thermocline water. J. Geophys. Res., 91, 5037-5050.

—, and W. F. Haxby, 1990: Agulhas eddies invade the South Atlantic: Evidence from Geosat altimeter and shipboard conductivity-temperature-depth survey. J. Geophys. Res., 95, 31173127

—, J. R. E. Lutjeharms, and M. L. Gründlingh, 1987: Stratification and circulation at the Agulhas retroflection. Deep-Sea Res., 34, 565-599.

— W. W. Ray, W. M. Smethie, and M. J. Warner, 1992: Thermocline and intermediate water communication between the South Atlantic and the Indian Oceans. J. Geophys. Res., 97, 7223-7240.

Gründlingh, M. L., 1996: Tracking eddies in the southeast Atlantic and southwest Indian Oceans with TOPEX/POSEIDON. J. Geophys. Res., 100, 24 377-24 986.

Harris, T. F. W., and D. Van Foreest, 1978: The Agulhas Current in March 1969. Deep-Sea Res., 25, 549-561.

Legeckis, R., and A. L. Gordon, 1982: Satellite observations of the Brazil and Falkland Currents-1975 to 1976 and 1978. DeepSea Res., 29, 375-401.

Lutjeharms, J. R. E., 1981: Features of the southern Agulhas Current circulation from satellite remote sensing. South Afr. J. Sci., 77, 231-236.

_ 1988: Examples of extreme circulation events at the Agulhas retroflection. South Afr. J. Sci., 84, 584-586.

, and R. C. van Ballegooyen, 1984: Topographic control in the Agulhas Current system. Deep-Sea Res., 31, 1321-1337.

- and A. L. Gordon, 1987: Shedding of an Agulhas ring observed at sea. Nature, 325, 138-140.

, and H. R. Roberts, 1988: The Natal Pulse: An extreme transient on the Agulhas Current. J. Geophys. Res., 93, 631-645.
—, and H. R. Valentine, 1988: Eddies at the subtropical convergence south of Africa. J. Phys. Oceanogr., 18, 761-774.

— and R. C. van Ballegooyen, 1988a: The retroflection of the Agulhas Current. J. Phys. Oceanogr., 18, 1570-1583.

$\longrightarrow$, and $-1988 \mathrm{~b}$ : Anomalous upstream retroflection in the Agulhas Current. Science, 240, 1770-1772.

— , and D. J. Webb, 1995: Modelling the Agulhas Current system with FRAM (Fine Resolution Antarctic model). Deep-Sea Res., 42, 523-551.

- D. J. Webb, B. A. De Cuevas, and S. R. Thompson, 1995: Large-scale modelling of the south-east Atlantic upwelling system. South Afr. J. Mar. Sci., 16, 205-225.

Matano, R. P., 1996: A numerical study of the Agulhas retroflection: The role of bottom topography. J. Phys. Oceanogr., 26, 22672279.

McCartney, M. S., and M. E. Woodgate-Jones, 1991: A deep-reaching anticyclonic eddy in the subtropical gyre of the eastern South Atlantic. Deep-Sea Res., 38, S411-S443.

Nilsson, C. S., and G. R. Cresswell, 1980: The formation and evolution of East Australia Current warm-core eddies. Progress in Oceanography, Vol. 9, Pergamon, 133-183.

— J. C. Andrews, and P. Scully-Power, 1977: Observations of eddy formation off East Australia. J. Phys. Oceanogr., 7, 659669.

Nof, D., 1981: On the $\beta$-induced movement of isolated baroclinic eddies. J. Phys. Oceanogr., 11, 1662-1672.

— Oceanogr., 26, 2344-2358

Olson, D. B., 1991: Rings in the ocean. Ann. Rev. Earth Planet. Sci., 19, 283-311.

— , and R. H. Evans, 1986: Rings of the Agulhas Current. DeepSea Res., 33, 27-42.

Ou, H. W., and W. P. M. de Ruijter, 1986: Separation of an inertial boundary current from a curved coastline. J. Phys. Oceanogr., 16, 280-289.

Pearce, A. F., 1977: Some features of the upper $500 \mathrm{~m}$ of the Agulhas Current. J. Mar. Res., 35, 731-751.

Pichevin, T., and D. Nof, 1997: The momentum imbalance paradox. Tellus, 49, 298-319.

Radko, T., and M. Stern, 1998: On the propagation of mesoscale vortices. J. Fluid Mech., in press.

Richardson, P. L., 1983: Gulf Stream rings. Eddies in Marine Science, A. R. Robinson, Ed., Springer-Verlag, 19-64.

Semtner, A. J., and R. M. Chervin, 1992: Ocean general circulation from a global eddy-resolving model. J. Geophys. Res., 97, 54935550.

Solomon, H., 1978: Detachment and recombination of a current ring with the Kuroshio. Nature, 274, 480-581.

Stramma, L., and R. J. Peterson, 1990: The South Atlantic Current. J. Phys. Oceanogr., 20, 846-859.

Veronis, G., 1973: Model of world ocean circulation: I. Wind-driven, two layer. J. Mar. Res., 31, 228-288.

Whitworth, T., III, and W. D. Nowlin Jr., 1987: Water masses and currents of the Southern Ocean at the Greenwich Meridian. $J$. Geophys. Res., 92, 6462-6476. 